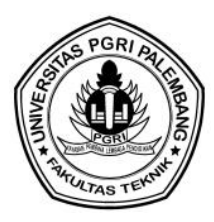

\title{
ANALISA KONTRIBUSI PERAN PEKERJAAN DALAM KEADAAN BERTEGANGAN (PDKB) TERHADAP PENINGKATAN KWH JUAL PADA PENYULANG VIRGO DI PT. PLN (PERSERO) WS2JB AREA LAHAT
}

\author{
Dian Eka Putra \\ Dosen Tetap Yayasan pada Program Studi Teknik Elektro \\ Fakultas Teknik Universitas Palembang \\ e-mail : dianeka.putra@ymail.com
}

\begin{abstract}
ABSTRAK
Listrik merupakan kebutuhan pokok yang tidak bisa ditinggalkan karena hampir 90\% dari kehidupan menggunakan listrik, sehingga PT. PLN (persero) harus berupaya keras untuk tetap menjaga pasokan listrik agar tetap tersalurkan. Seiring berjalannya waktu banyak persoalan yang dihadapi yaitu sering terjadinya padam. Padam dalam artian putusnya aliran listrik ke pelanggan baik dikarenakan pemeliharaan dan perbaikan atau dikarenakan gangguan. Pemadaman karena pemeliharaan dan perbaikan dapat dilakukan dengan PDKB atau Pekerjaan Dalam Keadaan Bertegangan. PDKB merupakan sebuah Tim yang berkompetensi untuk melakukan pekerjaan yang notabene tanpa memadamkan aliran listrik Keuntungan yang diperoleh jika meminimal kan padam, menekan rasio SAIDI dan SAIF, kWh salur tidak berkurang, rupiah jual tidak berkurang, serta yang paling penting pelayanan terhadap pelanggan akan semakin baik, maka semakin sering listrik mengalir maka semakin banyak pendapatan untuk perusahan.
\end{abstract}

Kata Kunci : PDKB, Saving kWh Jual, SAIDI dan SAIFI

\section{PENDAHULUAN}

Semakin bertambahnya pertumbuhan listrik memicu perusahaan listrik untuk menjaga kestabilan dan keandalan dari sistem tenga listrik. Masalah terbesar yang dapat mempengaruhi kestabilan dan keandalan sistem tenaga listrik adalah gangguan. Dimana sistem distribusi tengangan menengah dan rendah adalah ujung tombak pemanfaatan energi listrik bagi kegiatan ekonomi dan kegiatan manusia pada umunya. Terdapat 639 ribu kwh listrik PLN Area Lahat yang terus bertambah \pm 70.600 / tahun tersambung ke jaringan distribusi dimana kita telah memiliki kewajiban untuk meningkatkan kualitas dan citra pelayanan perusahaan dalam upaya melayani semua pelanggan PT PLN (Persero ).

Pelanggan yang dimaksud terbagi dalam dua kategori, pelanggan internal dan pelanggan external. Pelanggan internal itu sendiri meliputi antar sesama pegawai, pegawai dengan atasan, pegawai dengan bawahan. Pelanggan external ini adalah pelanggan yang berlangganan dengan PT PLN (Persero) dalam mengkonsumsi tenaga listrik, pelanggan ini juga mempunyai berbagai macam karakteristik, dimana seluruh pelanggan pada hakikatnya ingin mendapatkan pelayanan yang baik dan prima sehingga secara berkesinambungan kita harus meningkatkan kualitas pelayanan [3]. Salah satu cara yang dilakukan oleh PLN adalah dengan memiliki tim khusus yang dapat melaksanakan pemeliharaan dan perluasan tanpa adanya pemadaman yaitu PDKB (Pekerjaan Dalam Keadaan Bertegangan). 
Dasar Hukum Pekerjaan Dalam Keadaan Bertegangan adalah Peraturan Menteri Energi dan Sumber Daya Mineral No: 001 Tahun 2005 yang berbunyi "Dalam upaya peningkatan pelayanan dengan mengurangi pemadaman listrik maka pekerjaan pemeliharaan dan perluasan TR s/d TET dapat dilaksanakan dalam keadaan bertegangan[4].

Untuk mencapai target tersebut dengan meminimalkan pemadaman baik pemeliharaan ataupun perbaikan yaitu menggunakan PDKB atau Pekerjaan Dalam Keadaan Bertegangan. PDKB adalah sebuah Tim yang berkompetensi untuk melakukan pekerjaan yang notabene tanpa memadamkan aliran listrik, baik itu sisi tegangan tinggi (PDKB GI/TET), tegangan menengah maupun tegangan rendah. Atas dasar itulah tulisan ini akan membahas Analisa Kontribusi Peran Pekerjaan Dalam Keadaan Bertegangan (PDKB) Terhadap Peningkatan kWh Jual Di PT. PLN (Persero) Area Lahat. Adapun tujuan penelitian untuk mendapakan nilai indeks SAIFI dan SAIDI yang berorientasi pada pelayanan pelanggan sehingga menekan rasio SAIFI dan SAIDI sebagai bentuk pelayanan prima kepada konsumen PLN terhadap terjadinya pemadaman aliran listrik dan mengetahui kinerja $\mathrm{kWh}$ jual/salur yang dilaksanakan dengan pemeliharaan jaringan oleh Tim PDKB di PT. PLN (Persero) Area Lahat periode tahun 2012-2014

\section{TINJAUAN PUSTAKA}

\section{Gangguan Distribusi Tenaga Listrik}

Jaringan distribusi merupakan bagian dari sistem tenaga listrik yang paling dekat dengan pelanggan. Ditinjau dari volume fisiknya, jaringan distribusi pada umumnya lebih panjang dibandingkan dengan transmisi dan jumlah gannguannya dalam kali per $100 \mathrm{~km}$ per tahun juga paling tinggi dibandingkan jumlah gangguan saluran transmisi. [2].Djiteng Marsudi.2006. Operasi Sistem Tenaga Listrik Bab V.2.6 Hal 341.

\section{Pemeliharaan SUTM}

Saluran Udara Tegangan Menengah (SUTM) adalah sarana instalasi tenaga listrik diatas tanah untuk menyalurkan tenaga listrik dari Gardu Induk (GI) ke Gardu distribusi.

a. Pengertian pemeliharaan adalah kegiatan yang meliputi:

- Perawatan/pemeriksaan

- Perbaikan

- Penggantian

- Pengujian

b. Tujuan pemeliharaan

- Mempertahankan kemampuan kerja peralatan.

- Memperpanjang umur peralatan.

- Menghilangkan, mengurangi resiko kerusakan.

- Mengembalikan kemampuan kerja peralatan.

- Mengurangi kerugian secara ekonomis.

- Memberi keyakinan keandalan operasinya. 


\section{Pengertian PDKB}

PDKB adalah melaksanakan pekerjaan pada jaringan listrik yang terdiri dari pemeliharaan, modifikasi dan rehabilitasi dimana jaringan tetap dalam keadaan bertegangan. Sehingga pelanggan PLN tetap bisa menikmati listrik tetap menyala walaupun sedang ada perbaikan/pemeliharaan jaringan distribusi dan transmisi.

\section{Persyaratan PDKB}

Syarat umum untuk Pekerjaan Dalam Keadaan Bertegangan (PDKB) harus berdasarkan[8]. Pedoman PDKB (Pedoman Umum Pemeliharaan Transmisi TT/TET dengan PDKB).Edisi 01 PT. PLN (Persero) Penyaluran dan Pusat Pengaturan Beban Jawa Bali 2005. Bab 2.1 Hal.7.

Prosedur dan Instruksi Kerja yang telah DISAHKAN, serta peralatan yang telah LULUS UJI oleh Lembaga Sertifikasi.

1. Penerima Surat Penunjukkan Pengawas Pekerjaan Bertegangan (SP3B) dan Surat Perintah melaksanakan Pekerjaan Bertegangan (SP2B) bertanggung jawab terhadap pelaksanaan PDKB, meliputi : Prosedur, Instruksi Kerja, Peralatan, dan Material yang digunakan.

2. Pelaksanaan PDKB adalah pengembangan dari pekerjaan padam (off line).

3. PDKB tidak boleh dilaksanakan pada pekerjaan yang tidak terencana.

4. Pengawas K3 bertanggung jawab atas keselamatan pelaksana, peralatan, dan pelaksanaan pekerjaan.

5. Keselamatan pribadi menjadi tanggung jawab masing-masing.

6. Dalam melaksanakan pekerjaan tidak diperbolehkan ada dua kegiatan yang dapat saling mempengaruhi pergerakan konduktor bila terjadi kegagalan peralatan atau material.

7. Semua peralatan harus lulus uji setiap 6 bulan sekali.

8. Semua pelaksana PDKB harus diperiksakan kesehatannya (general check up) setiap satu tahun sekali

\section{Metode PDKB}

Dalam pelaksanaannya PDKB memakai 2 macam metode yang digunakan yaitu metode barehand (Sentuh langsung) dan Metode Hot Stick (Tongkat Berisolasi).

\section{Metode Barehand (Sentuh Langsung)}

Teknis untuk pekerjaan dengan metode barehand sudah dikenal dari tahun 1837. Pada tahun tersebut Michael Faraday membuat suatu penemuan bahwa suatu ruang tertutup yang terbuat dari bahan-bahan penghantar listrik. Ruangan itu mampu merintangi medan listrik statik eksternal. Medan listrik statik eksternal akan menyebabkan muatan listrik di dalam bahan yang konduktif untuk menyalurkan kembali diri mereka sendiri. Hal ini kemudian membatalkan efek medan listrik statik di bagian dalam sangkar, teori ini disebut Sangkar Faraday.

Dengan menggunakan teori tersebut, seorang pekerja dapat dialiri listrik/bermuatan listrik pada tegangan tinggi, apabila dilindungi dalam sebuah sangkar Faraday, yang diikat /dihubungkan ke konduktor bertegangan dan dapat bekerja dalam konduktor. 
Pada metode barehand diwajibkan bagi para pelaksana untuk memakai sarung tangan berisolasi, sarung lengan berisolasi, sepatu kerja berisolasi dan mobil berisolasi..

\section{Metode Hot Stick (Tongkat Berisolasi)}

Metode Hot Stick adalah suatu metode dimana pelaksana berada di sisi tower yang terisolasi dari konduktor bertegangan. Metode ini menggunakan peralatan hot stick dengan jarak tertentu sehingga aman dikerjakan. Metode hot stick dapat juga digunakan bersamaan dengan metode barehand selama metode tersebut bisa saling melengkapi.Hot stick yang digunakan pada metode ini terbuat dari Fibreglass Reinforced Plastic (FRP) yaitu plastik yang diperkuat dengan fiberglass.[8]. Pedoman PDKB (Pedoman Umum Pemeliharaan Transmisi TT/TET dengan PDKB).Edisi 01 PT. PLN (Persero) Penyaluran dan Pusat Pengaturan Beban Jawa Bali 2005. Bab 2.3.2 Hal.8

\section{Pengawas Pelaksanaan PDKB}

Dalam setiap pelaksanaan PDKB, terdapat dua macam pengawas yaitu Pengawas Pekerjaan dan Pengawas K3. Tujuan pengawasan adalah untuk memperoleh hasil pelaksanaan pekerjaan yang sesuai dengan standar mutu.

\section{Prosedur \& Instruksi Kerja}

Prosedur kerja merupakan prosedur baku pada setiap pelaksanaan pekerjaan PDKB yang telah disetujui oleh para/pelaksana/pekerja yang terlibat dalam PDKB dan disahkan oleh manajemen yang berwenang, prosedur dapat direvisi sesuai dengan kondisi lapangan terkini melalui pelatihan secara off-line terlebih dahulu. [8].Pedoman PDKB (Pedoman Umum Pemeliharaan Transmisi TT/TET dengan PDKB).Edisi 01. PT. PLN (Persero) Penyaluran dan Pusat Pengaturan Beban Jawa Bali 2005.Bab.2.6.1.hal 15.

1. Prosedur dan Instruksi kerja harus didiskusikan dengan semua anggota tim pelaksana PDKB selama sesi briefing pada awal dan akhir pekerjaan.

2. Prosedur dan Instruksi kerja tersebut tidak boleh diubah selama pelaksanaan PDKB berlangsung. Perubahan prosedur dan instruksi kerja harus dilakukan berdasarkan penelitian menyeluruh dan dikembangkan oleh pelaksana/pekerja PDKB yang bersertifikat dan berpengalaman, dan dibuktikan secara off-line maupun on-line, dan disahkan secara formal.

\section{Jarak Aman Minimum PDKB (Live Line Minimum Approach Distance/LLMAD)}

Jarak aman minimum adalah daerah dimana pelaksana dapat bekerja dan peralatan dapat digunakan dengan aman pada daerah bertegangan. Pelaksana PDKB harus tetap menjaga dirinya dan peralatan yang dibawanya agar tidak melanggar jarak aman minimum dan jarak minimum peralatan. Jarak aman biasanya dalam PDKB TM Metode Berjarak disebut dengan istilah Elemen Pelindung. Pelaksana Pekerjaan harus mentaati jumlah minimal Elemen Pelindung (EP) antara ruang bebas gerak pelaksana dengan bagiang jaringan yang bertegangan sebagai berikut : 
Tabel 1. Elemen Pelindung

\begin{tabular}{|l|l|l|}
\hline Tegangan & $\mathrm{U}<20 \mathrm{kV}$ & $\begin{array}{l}20 \mathrm{kV}<\mathrm{U}<26 \\
\mathrm{kV}\end{array}$ \\
\hline $\begin{array}{l}\text { Jarak Aman (Elemen } \\
\text { Pelindung) }\end{array}$ & $6 \mathrm{EP}$ & $8 \mathrm{EP}$ \\
\hline \multicolumn{2}{|l|}{$1 \mathrm{EP}=10 \mathrm{~cm}$} &
\end{tabular}

Daerah terlarang bagi pelaksana adalah daerah dimana pelaksana tidak dapat masuk tanpa sesuai dengan tingkatan dan hanya dapat memasukkan perkakas atau peralatan yang sesuai dengan pekerjaan bertegangan.[7.] Pelaksana PDKB TM B.1.1.3.24.3 PT. PLN (Persero).VI.hal.80]

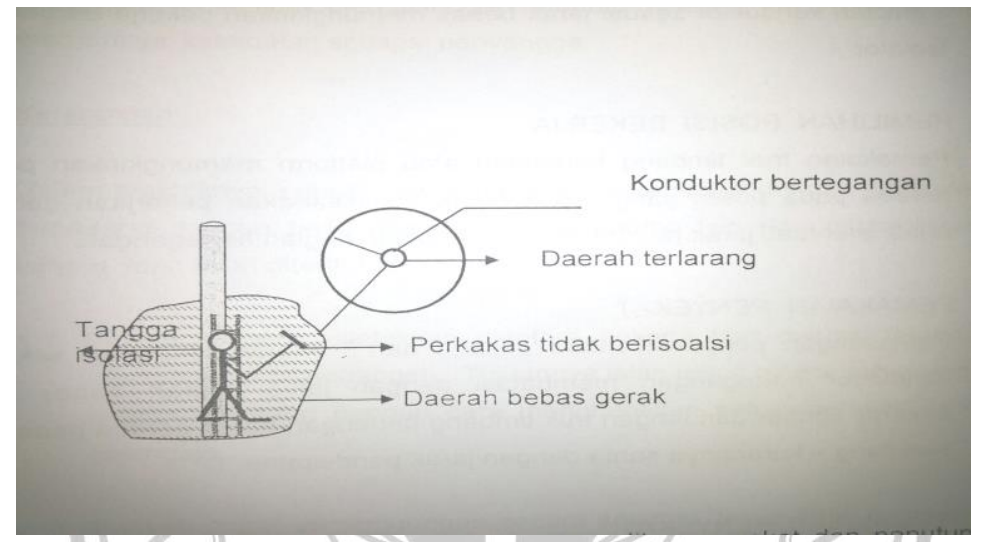

\section{Gambar 1. Ilustrasi Daerah Terlarang}

\section{Persyaratan Peralatan Kerja PDKB}

1. Semua perlengkapan dan peralatan harus mempunyai nilai Beban Aman Minimum (BAM) dari pabrikannya.

2. Beban aman minimum adalah beban maksimum peralatan yang diijinkan sesuai dengan Faktor Keselamatan(FK).

3. Faktor Keselamatan (FK) adalah perbandingan antara beban patah/putus perlatan (BPP) dengan batas aman minimum (BAM).

$$
\mathrm{FK}=\frac{\mathrm{BPP}}{\mathrm{BAM}}
$$

4. Faktor keselamatan pada setiap pekerjaan berpengaruh juga pada jumlah personil pelaksanaan pekerjaan. Minimum jumlah pelaksana pekerjaan adalah 7 (tujuh) orang, yang terdiri dari 1 (satu) orang pengawas pekerjaan, 1 (satu) orang pengawas K3 dan 5 (lima) Orang pelaksana/linesman yang bisa bergantian pada pekerjaan.

\section{Standar Perhitungan Waktu PDKB TM}

Standar perhitungan waktu pelaksanaan PDKB TM diambil dari waktu pelaksanaan offline pemeliharaan rata-rata dengan satuan jam. Seperti tabel 2.2 dibawah ini. 
Tabel 2. Standar Perhitungan Waktu Pelaksanaan PDKB TM

\begin{tabular}{|c|c|c|c|}
\hline No & Jenis Pekerjaan & $\begin{array}{c}\text { Waktu } \\
*)\end{array}$ & $\begin{array}{c}\text { Kriteria } \\
* *)\end{array}$ \\
\hline 1 & $\begin{array}{l}\text { Pemasangan/perbaikan Pole Top Switch (PTS)/Load Break } \\
\text { Switch (LBS) }\end{array}$ & 5 & a \\
\hline 2 & Pemasangan/pemeliharaan jumper & 2 & $\mathrm{a}$ \\
\hline 3 & Perbaikan sagging/andongan per seksi & 3 & $\mathrm{a}$ \\
\hline 4 & Pemasangan/pemeliharaan PT dan CT & 3 & $\mathrm{a}$ \\
\hline 5 & Mengganti/pasang baru tiang + konstruksi & 4 & $\mathrm{a}$ \\
\hline 6 & Merubah konstruksi & 5 & $\mathrm{a}$ \\
\hline 7 & Perbaikan/pemasangan Recloser/Disconnecting Switch & 5 & $\mathrm{a}$ \\
\hline 8 & Penggantian/pemeliharaan Fuse Cut Out & 3 & $\mathrm{a}$ \\
\hline 9 & Pemeliharaan Trafo dengan Unit Gardu Bergerak (UGB) & 4 & $\mathrm{a}$ \\
\hline 10 & Pemasangan Threeguard 1 buah & 1 & $\mathrm{a}$ \\
\hline 11 & Pemasangan/penambahan Voorlinkstuck 1 tiang & 3 & $\mathrm{a}$ \\
\hline 12 & Pemasangan/penggantian Cross Arm/Travers & 3 & a \\
\hline 13 & Merubah konstruksi Gardu type portal & 5 & $\mathrm{a}$ \\
\hline 14 & Bongkar/pasang Jumper Cable Outdoor & 3 & a \\
\hline 15 & $\begin{array}{l}\text { Potong dan pasang Jumper CO untuk penggantian Trafo } 1 \\
\text { Fasa }\end{array}$ & & $\mathrm{b}$ \\
\hline 16 & $\begin{array}{l}\text { Potong dan pasang Jumper CO untuk penggantian Trafo } 3 \\
\text { Fasa }\end{array}$ & & $\mathrm{b}$ \\
\hline 17 & Sambungan baru JTM 3 fasa & 3 & $\mathrm{~b}$ \\
\hline 18 & Penggantian/pemasangan trafo 3 fasa bank & 3 & $\mathrm{~b}$ \\
\hline 19 & Penggantian/pemasangan trafo 3 fasa konvensional & 4 & $\mathrm{~b}$ \\
\hline 20 & 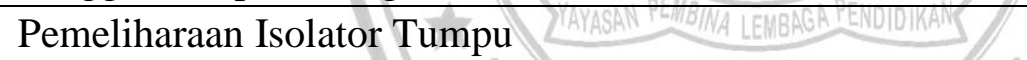 & 2 & $\mathrm{~b}$ \\
\hline 21 & Pemeliharaan Isolator Gantung & 2 & $\mathrm{~b}$ \\
\hline 22 & Pemeliharaan Isolator Dead End- & 2 & $\mathrm{~b}$ \\
\hline 23 & Perbaikan konduktor SUTM terurai/rantas per gawang & 2 & $\mathrm{~b}$ \\
\hline 24 & Pemasangan/penggantian Lightning Arrester 3 Fasa & 2 & $\mathrm{~b}$ \\
\hline 25 & Pemasangan/pemeliharaan penangkal petir 1 set & 2 & $\mathrm{~b}$ \\
\hline 26 & Perbaikan Tiang Miring & 3 & $\mathrm{~b}$ \\
\hline 27 & Penggantian/pemasangan trafo 1 fasa & 2 & $\mathrm{~b}$ \\
\hline 28 & Pengecatan Tiang Besi & 1 & $\mathrm{c}$ \\
\hline 29 & Bongkar/pasang Fault Indicator Overhead Line & 1 & $\mathrm{c}$ \\
\hline 30 & Penggantian Arm Tie & 1 & $\mathrm{c}$ \\
\hline 31 & Rabas-rabas ranting pohon 1 gawang & 2 & $\mathrm{c}$ \\
\hline 32 & Perbaikan Trackschoor/Drakschoor & 1 & $\mathrm{c}$ \\
\hline 33 & Sambungan baru JTM 1 fasa & 2 & $\mathrm{c}$ \\
\hline $\begin{array}{l}*) \\
*))\end{array}$ & \multicolumn{3}{|l|}{$\begin{array}{l}\text { Pembobotan Tingkat Kesulitan } \\
\mathrm{a}=4 ; \mathrm{b}=3 ; \mathrm{c}=2\end{array}$} \\
\hline
\end{tabular}




\section{Perhitungan Beban pada jaringan SUTM yang dilaksanakan dengan PDKB dan kWh yang diselamatkan}

Perhitungan beban pada penyulang dapat dirumuskan dengan:

$$
I=\frac{\text { Plgn } \times P \text { rata-rata }}{U \times \sqrt{3} \times \operatorname{Cos} Q}
$$

Keterangan :

$\begin{array}{ll}\mathrm{I} & =\text { Beban pada jaringan (Ampere) } \\ \text { Plgn } & =\text { Jumlah Pelanggan pada Jaringan tersebut (Pelanggan) } \\ \text { P rata-rata } & =\text { Daya pemakaian rata-rata pelanggan (VA) } \\ \text { U } & =\text { Tegangan pada jaringan }(\mathrm{V}) \\ \sqrt{3} & =1,73 \\ \text { Cos } Q & =0,85\end{array}$

Sehingga untuk menghitung $\mathrm{kWh}$ yang diselamatkan dan dirumuskan sebagai berikut :

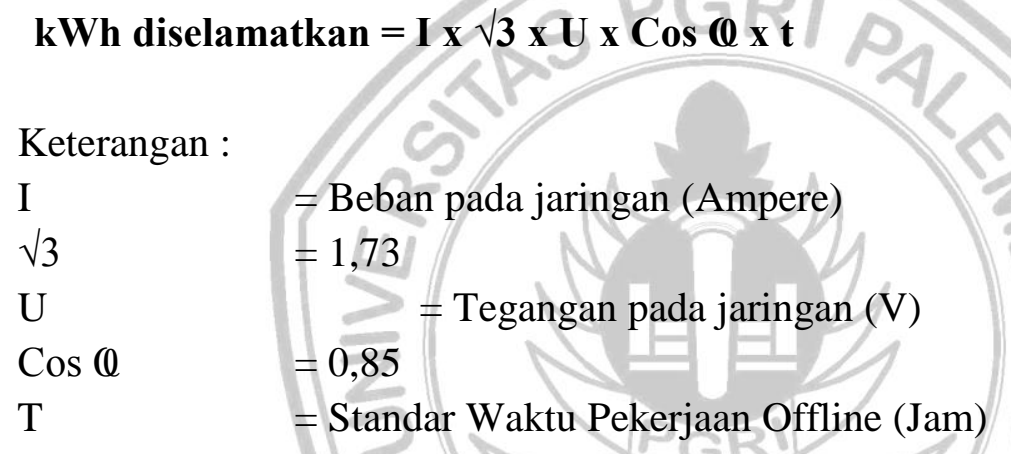

Dari hasil tersebut didapatkan Rupiah yang diselamatkan yang dapat dirumuskan sebagai berikut :

$$
\begin{aligned}
& \text { Rp diselamatkan } \quad=\mathbf{k W h} \text { diselamatkan } \mathbf{x}(\mathbf{R p} / \mathbf{k W h}) \\
& \text { Keterangan : } \\
& \text { Rp/kWh = Total Rupiah Jual Unit / Total } \mathrm{kWh} \text { Jual Unit }
\end{aligned}
$$

Setiap pelaksanaan pekerjaan PDKB selesai, maka secara tidak langsung perusahaan akan mendapatkan $k W h$ saving. Secara umum $k W h$ saving PDKB adalah keuntungan finansial yang diperoleh dari aktivitas PDKB. Keuntungan tersebut berupa :

- Penghematan biaya operasi (Rp)

- Meningkatkan kWh jual

- Peningkatan Pendapatan Rupiah

- Memaksimalkan tingkat ketersediaan kapasitas pelayanan

- Kontinuitas Pelayanan kepada Pelanggan tetap terjaga

- Meningkatkan Citra Pelayanan kepada Pelanggan 


\section{Rasio SAIDI - SAIFI}

\section{System Avarage Interruption Frequency Index (SAIFI)}

SAIFI merupakan suatu indeks yang menyatakan banyaknya gangguan (pemadaman) yang terjadi pada pelanggan dalam suatu sistem secara keseluruhan, baik itu pemadaman akibat gangguan ataupun akibat pemeliharaan.[3]Pokja Keandalan WCS.Keandalan(menuju world class service 2015.Bab II.2.2.hal4. Adapun rumus nya sebagai berikut :

\section{SAIFI $=\frac{\text { Jumlah Kali Pelanggan Padam }}{\text { Jumlah Pelanggan Total }}$}

\section{System Avarage Interruption Duration Index (SAIDI)}

SAIDI merupakan suatu indek yang menyatakan lamanya gangguan (pemadaman) yang terjadi pada pelanggan dalam suatu sistem secara keseluruhan. jumlah durasi gangguan pelanggan, baik itu pemadaman akibat gangguan ataupun akibat pemeliharaan. [3]Pokja Keandalan WCS.Keandalan(menuju world class service 2015.Bab II.2.2.hal4.. Adapun rumus nya sebagai berikut :

\section{SAIDI $=$ Jumlah Lama Pelanggan Padam}

\section{METODE PENELITIAN}

Berdasarkan penelitian di PT. PLN (persero) WS2JB Area Lahat dari Penyulang Virgo yang memiliki jumlah pelanggan 10.399. Penelitian ini di laksanakan untuk menjaga agar pelanggan masih merasakan listrik menyala pada saat pemeliharaan jaringan dilakukan. Pengambilan data dilakukan dengan observasi lapangan di PT. PLN (persero) WS2JB Area Lahat di Penyulang Virgo di PT. PLN (persero) WS2JB Area Lahat di Penyulang Virgo ini dilakukan pada tanggal 01 April 2015 sampai dengan 30 April 2015, sehingga bisa mendapatkan data-data yang dibutuhkan untuk penelitian ini.

\section{HASIL DAN ANALISA}

Dari hasil survey yang dilakukan dilapangan maka diperoleh data-data yang akan di kelola yaitu :

\section{Data Analisa Jaringan yang akan dilaksanakan dengan PDKB}

Pada Penyulang Virgo :

Jumlah pelanggan $\quad=10.399$ pelanggan

Tegangan $\quad=20 \mathrm{kV}$

Cos $Q \quad=0,85$

Total Standar waktu pelaksanaan pekerjaan dengan Offline $=66 \mathrm{Jam}$

Dengan estimasi daya pada pelanggan rata-rata siang adalah $450 \mathrm{Watt}$

Beban pada penyulang Virgo tersebut adalah :

$$
I=\frac{\text { Plgn } \times \text { P rata-rata }}{U \times \sqrt{3} \times \operatorname{Cos} Q}
$$




$$
\begin{aligned}
& I=\quad \begin{array}{rrrrr}
10.399 & x & \multicolumn{2}{c}{450} \\
\hline 20.000 & x & 1,73 & x & 0,85
\end{array} \\
& I=\frac{4.679 .550}{29.410} \\
& \mathrm{I}=\quad 159 \mathrm{~A}
\end{aligned}
$$

Tabel 3. Data Rencana Pekerjaan PDKB

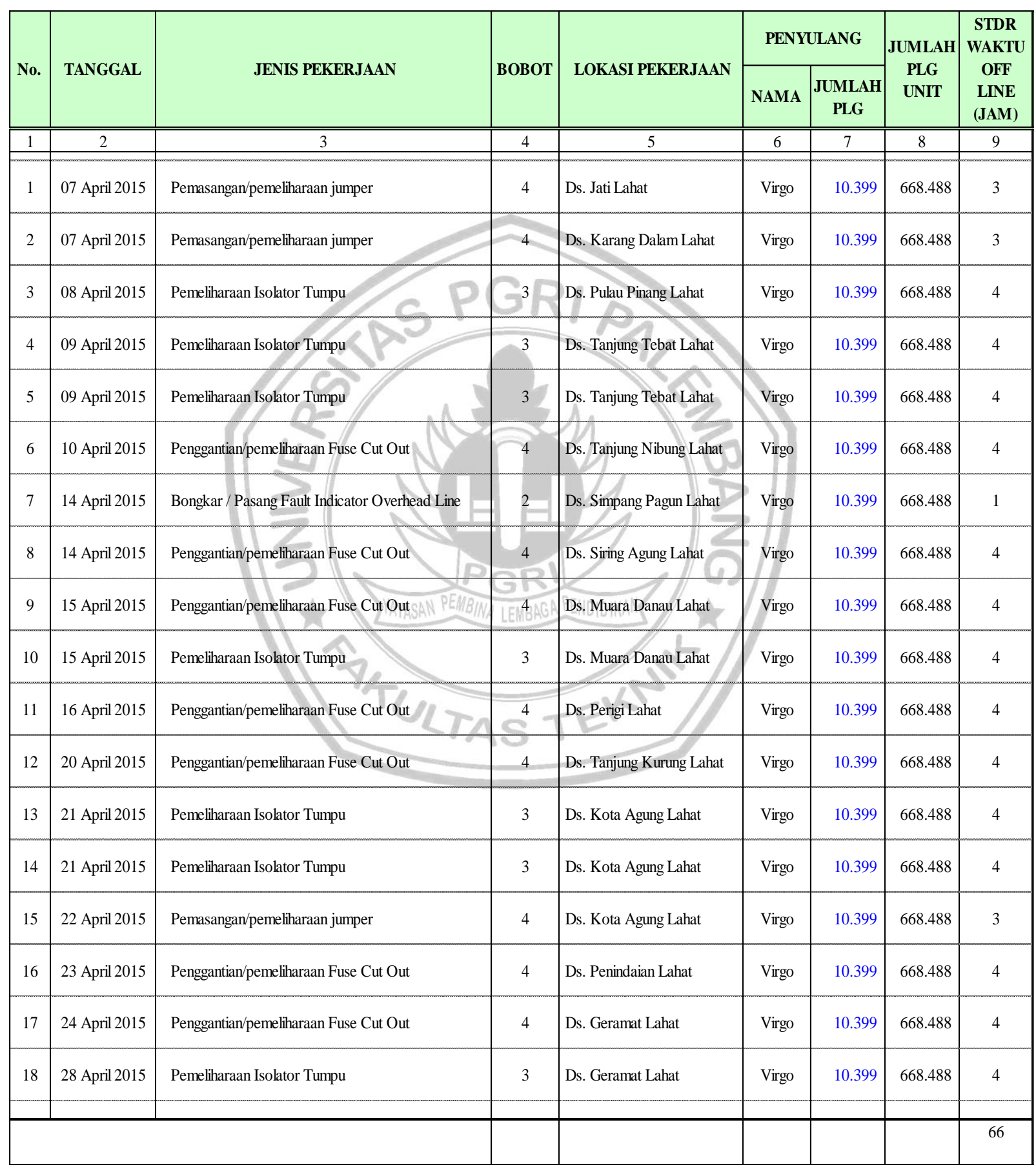


Sehingga $\mathrm{kWh}$ yang diselamatkan adalah :

$\mathbf{k W h}$ diselamatkan $=I \times \sqrt{ } \mathbf{3} \times \mathrm{U} \times \operatorname{Cos} \boldsymbol{Q} \times \mathbf{t}$

$\begin{array}{rlccccccccc}\mathrm{kWh} \text { yang diselamatkan } & = & 159 & \mathrm{x} & 1,73 & \mathrm{x} & 20 & \mathrm{x} & 0,85 & \mathrm{x} & 66 \\ & = & 308.629 & & \mathrm{kWh}\end{array}$

Dari perolehan $\mathrm{kWh}$ yang diselamatkan diatas maka dapat dicari berapa Rupiah yang didapatkan selama pekerjaan tersebut : dengan asumsi $\mathrm{Rp} / \mathrm{kWh}=773,53$

Rp diselamatkan $=\mathbf{k W h}$ diselamatkan $x(\mathrm{Rp} / \mathrm{kWh})$

$$
\begin{array}{rlcrr}
\text { Rp yang diselamatkan } & = & 308.629 & \times & 773,53 \\
& = & \text { Rp.238.733.43 } & & \\
& & 5 & \text { Rupiah }
\end{array}
$$

Jadi dalam pelaksanaan pekerjaan PDKB tersebut dalam 13 hari dengan jumlah 18 titik pekerjaan bisa menyelamatkan/menyalurkan $308.629 \mathrm{kWh}$ kepada pelanggan dengan perolehan Rp. 238.733.435,-

Apabila pekerjaan tersebut dilaksanakan dengan cara pemeliharaan offline selama 13 hari maka 308.629 kWh tidak tersalurkan ke pelanggan dan PLN Area Lahat akan kehilangan omzet penjualan tenaga listrik sebesar Rp. 238.733.435,--

\section{Rasio SAIDI dan SAIFI}

Dari data analisa diatas dapat kita ketahui SAIDI dan SAIFI yang dialami pelanggan apabila pekerjaan tersebut tidak dilaksanakan dengan PDKB. Adapun kontribusi PDKB terhadap PDKB dapat kita cari dengan rumus sebagai berikut :

$$
\text { SAIDI }=\frac{\text { Jumlah Lama Pelanggan Padam }}{\text { Jumlah Pelanggan Total }}
$$

Jumlah pelanggan total $=668.488$ pelanggan

$$
\begin{aligned}
\text { SAIDI } & =\frac{10.399 \times}{668.488} \\
& =\frac{686.334}{668.488} \text { Jam (Standar Pekerjaan Offline) } \\
& =1,0267 \\
& =1,0267 \quad \mathrm{x} \quad 60 \quad \text { Menit } \\
& =61,60 \quad \text { Menit / Pelanggan }
\end{aligned}
$$




$$
\begin{aligned}
\text { SAIFI } & =\frac{\text { Jumlah Kali Pelanggan Padam }}{\text { Jumlah Pelanggan }} \\
\text { SAIFI } & =\frac{10.399}{668.488} \\
& =0,02 \\
& =0,02 \quad \mathrm{X} \quad 18 \quad \text { kali pekerjaan } \\
& =0,28 \quad \mathrm{Kali} \text { Padam / Pelanggan }
\end{aligned}
$$

Dari hasil perhitungan diatas dapat kita lihat grafik kontribusi PDKB terhadap SAIDI dan SAIFI pelanggan, seperti dibawah ini :

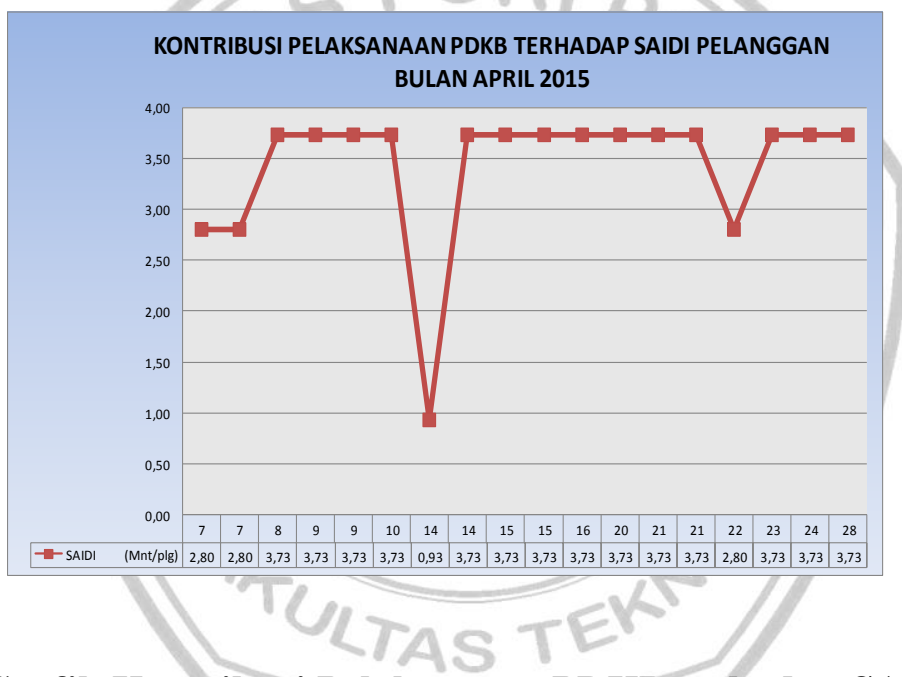

Gambar 2. Grafik Kontribusi Pelaksanaan PDKB terhadap SAIDI Pelanggan

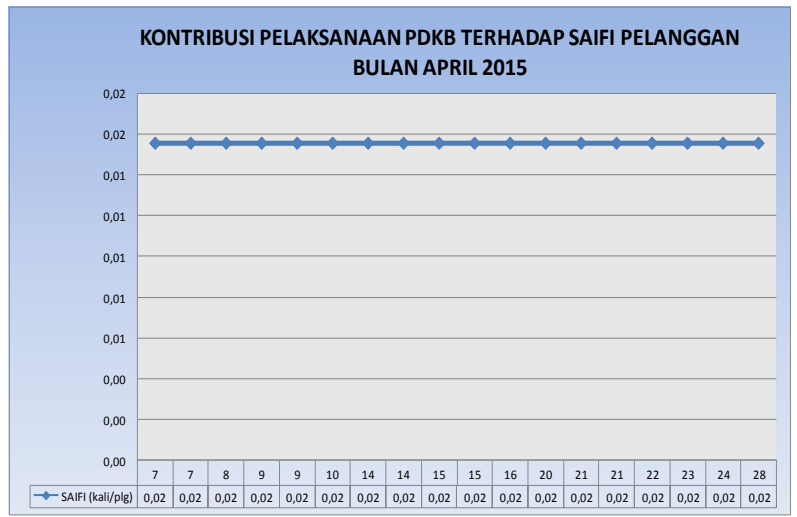

Gambar 3. Grafik Kontribusi Pelaksanaan PDKB terhadap SAIFI Pelanggan 
Tabel 4. Data Pelaksanaan PDKB Tahun 2014

\begin{tabular}{|r|l|r|r|r|l|}
\hline \multirow{2}{*}{ No } & \multirow{2}{*}{ Bulan } & \multicolumn{3}{|c|}{ Kontribusi PDKB } & \multirow{2}{*}{ Keterangan } \\
\cline { 3 - 6 } & & Titik Kerja & KWh diselamatkan & $\begin{array}{c}\text { Prakiraan Rp } \\
\text { terselamatkan }\end{array}$ & \\
\hline 1 & Januari & - & - & - & \\
\hline 2 & Februari & 75 & 718.640 & 557.060 .756 & \\
\hline 3 & Maret & 25 & 113.183 & 81.518 .734 & \\
\hline 4 & April & 7 & 104.644 & 76.520 .907 & \\
\hline 5 & Mei & 20 & 94.103 & 68.812 .836 & \\
\hline 6 & Juni & - & - & & \\
\hline 7 & Juli & 17 & 70.872 & 53.995 .028 & \\
\hline 8 & Agustus & 12 & 64.659 & 50.015 .695 & \\
\hline 9 & September & 8 & 77.114 & 60.809 .658 & \\
\hline 10 & Oktober & 8 & 35.804 & 29.121 .463 & \\
\hline 11 & Nopember & 7 & 174.662 & 140.796 .630 & \\
\hline 12 & Desember & 7 & 43.695 & 35.222 .893 & \\
\hline & Jumlah & $\mathbf{1 8 6}$ & $\mathbf{1 . 4 9 7 . 3 7 5}$ & $\mathbf{1 . 1 5 3 . 8 7 4 . 6 0 0}$ & \\
\hline
\end{tabular}

Perolehan kWh jual perusahaan yang diselamatkan oleh pelaksanaan PDKB tahun 2014 adalah 1.497.375 kWh dan Pendapatan perkiraan Rupiah yang diselamatkan bagi perusahaan adalah Rp. 1.153.874.600,-.

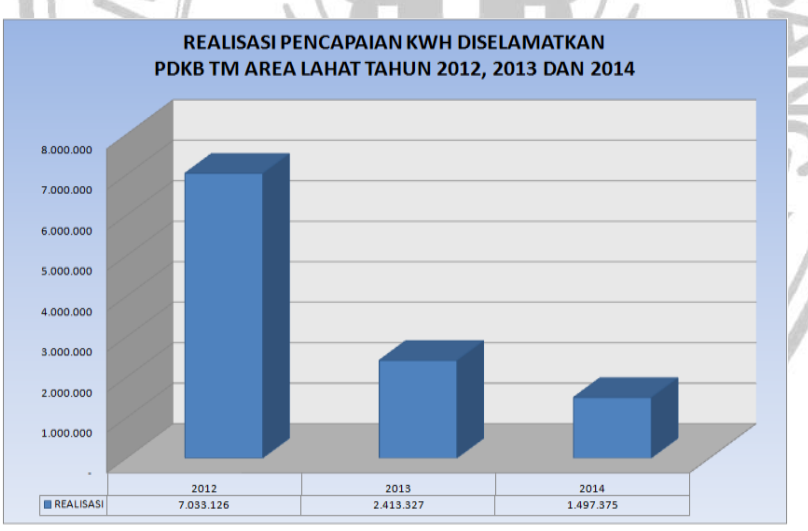

Gambar 4. Realisasi Pencapaian kWh terselamatkan oleh PDKB Tahun 2012 sd 2014

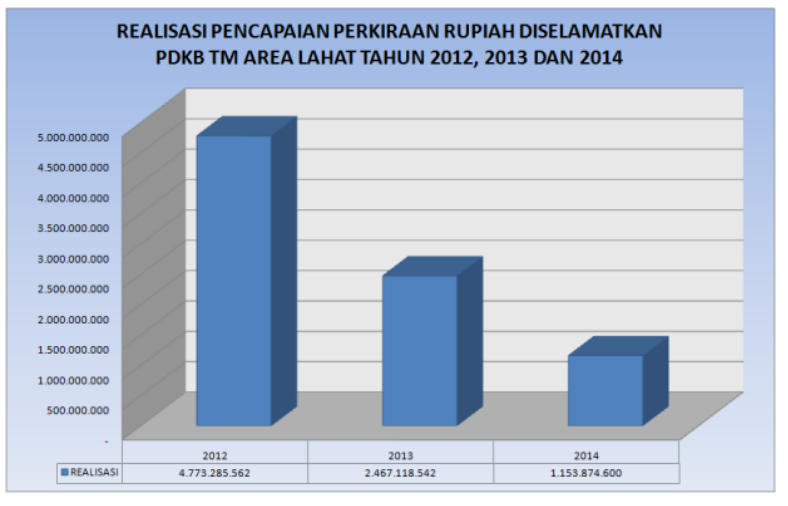

Gambar 5. Realisasi Pencapaian Perkiraan Rupiah terselamatkan oleh PDKB Tahun 2012 sd 2014 
Perolehan $\mathrm{kWh}$ jual perusahaan yang diselamatkan oleh pelaksanaan PDKB dari tahun 2012 sampai dengan 2014 adalah $10.943 .828 \mathrm{kWh}$ dan Pendapatan perkiraan Rupiah yang diselamatkan bagi perusahaan adalah Rp. 8.394.278.703,--

\section{KESIMPULAN}

Berdasarkan hasil penelitian dapat disimpulkan bahwa ada empat manfaat yang diharapkan dapat dicapai dengan pelaksanaan PDKB yaitu menekan angka rasio SAIDI \& SAIFI pada bulan April 2015 dengan nilai rata-rata SAIDI 61,6 menit/pelanggan dan SAIFI $0,28 \mathrm{kali}$ padam/pelanggan. Serta dengan peningkatan penjualan $\mathrm{kWh}$ salur kepada pelanggan sebesar $308.629 \mathrm{kWh}$ dan pendapatan perusahaan sebesar Rp. 238.733.435,- pada bulan April 2015.

\section{DAFTAR PUSTAKA}

1. Brown, E. Richard. 2002, Electric Power Distribution Reliability, New York. Basel : Marcel Dekker, Inc

2. Marsudi, Djiteng. Edisi II. 2006, Operasi Sistem Tenaga Listrik, Yogyakarta: Graha Ilmu.

3. Pokja Keandalan WCS. Edisi II. 2013, Keandalan (Menuju world class service 2015) PT. PLN (Persero) Distribusi, Jawa Timur.

4. SPLN 82-1. 1991. Pekerjaan Dalam Keadaan Bertegangan Bagian 1 peraturan umum. PT. PLN (Persero).

5. SPLN 82-3. 1991. Pekerjaan Dalam Keadaan Bertegangan Bagian 2 Jaringan Tegangan Rendah, Persyaratan Kerja dan Lembar teknik perkakas. PT. PLN (Persero).

6. SPLN 82-3. 1991. Pekerjaan Dalam Keadaan Bertegangan Bagian 3 Lembar Teknik Perkakas dan lembar teknik - metode operasi. PT. PLN (persero).

7. B.1.1.3.24.3 2009. Pelaksana PDKB TM PT. PLN (Persero) Pusat Pendidikan dan Pelatihan.

8. Team PDKB.2005. Pedoman PDKB (Pedoman Umum Pemeliharaan Transmisi TT/TET dengan PDKB).Edisi 01. PT. PLN (Persero) Penyaluran dan Pusat Pengaturan Beban Jawa Bali.

9. Website PDKB, “ http://pdkb.pln-pusdiklat.co.id/ “ 